\title{
On the north sea shore
}

\author{
Sobre a Costa do Mar do Norte
}

\section{Charles Travis* $^{*}$}

King's College London, London, UK

\section{Abstract}

A thought makes truth turn in some given way on how things are. What it thus does decomposes in partial doings of this. For example, making truth turn on whether Sid is sober may decompose into making truth turn on which ways Sid is, and on which objects are sober. If we assume that a thought decomposed in just one such way. Such, then, would be a thought's essential structure. That idea might then apply as follows. To hold a thought true one must first grasp it. To grasp it one must each element of its essential structure. If, say, those elements are making truth turn on Sid and making it turn on who is sober, then one must grasp what it would be for something to be Sid (and for something to be sober). The working assumption here is false. But in any case this application is mistaken. Or so this essay argues.

Keywords: Thoughts. Concepts. Grasping. Structure.

* CT: Doctor, e-mail: c.s.travis@gmail.com 


\section{Resumo}

Um pensamento faz a verdade se tornar uma dada forma sobre como as coisas são. O que, portanto, se decompõe em acontecimentos parciais desta. Por exemplo, fazer a verdade acerca de se Sid é sóbrio pode se decompor em fazer a verdade acerca de quais são as formas de Sid e quais objetos são sóbrios. Se assumirmos que um pensamento decompôs em só uma tal maneira. Tal, seria então uma estrutura essencial de um pensamento. Esta ideia pode então se aplicar da seguinte maneira: para um pensamento verdadeiro ser sustentado precisa-se entendê-lo. Para compreendê-lo, deve-se decompor cada elemento da sua estrutura essencial. Se, digamos, esses elementos estão fazendo a verdade acerca de Sid e fazendo-a acerca de quem é sóbrio, então é preciso entender o que seria para Sid ser sóbrio (e para algo estar sóbrio). O pressuposto do trabalho aqui é falso. Mas, em qualquer caso, este ensaio está enganado. Ou então, este ensaio argumenta.

Palavras-chave: Pensamentos. Conceitos. Entendimento. Estrutura.

Grasping a thought presupposes a grasper, a thinker. He is thus the source of the thinking, not of the thought. Although the thought does not belong to the content of the thinker's consciousness, still there must be something in his thinking, which is aimed at it. But this must not be confused with the thought itself (Frege, 1918, 75).

A thought, Frege tells us, is "that by which truth can come into question at all" (1918, p. 60; 1919, p. 273). A thought is thus something abstracted from thinking, and from thought-expression, in order to identify that on which laws of logic (or laws of truth) can get a grip: that which stands in relations to others of its sort merely by virtue of what being true is as such. Late in his career, summing up his main ideas, Frege also tells us this:

If someone acknowledges something as true, he thus judges it. What he acknowledges as true is a thought. One cannot acknowledge a thought as true before he grasps it $(1915,271)$. 
It remains to be said when someone might count as having grasped a thought. Here is one idea: to grasp (and hence, by the above, to think) the thought that lamprey spawn in the Minho, you must know which river the Minho is, and what a lamprey, and what spawning are. But is this right? Whatever your answer, it had better square with this: for Pia to think that lamprey spawn in the Minho is for her to be the same as mosts of us (hereabouts) who also think so. She must be the same, that is, in relevant respects; on the relevant understanding of the same (since same always calls for some more particular understanding). So we must ask: In what ways must Pia be the same as (most of) the rest of us if she is to count as sharing with us this belief about the Minho (or about lamprey)? Anyway, this is not something for her to say. For Pia to be relevantly the same as most of the rest of us. For her to know the ways of lamprey as we do, is for her to agree with us on the point in question. But exactly what point is that? And what might agreement come to? Feeling our way around this last question, we can quickly enough come to see that that initial idea about grasping, however intuitive it must at first seem, cannot be right. When we carve a thought into elements we may carve out of it a variety of concept, that is, various ways for an object, or objects, to be. But grasp of the thought (the ability to think it) does not entail grasp of any one of these. Such shows something as to how thoughts decompose.

\section{Thinking Things:}

Frege wrote,

Number is as little a topic for psychology, or a product of psychological processes as, say, the North Sea. The objectivity of the North Sea is not compromised by the fact that it depends on our arbitrary choice which part of all the water covering the earth we mark off and to which we want to allot the name 'North Sea'. Such is no reason to want to investigate this sea by psychological means. So, too, is number something objective. If one says, 'The North Sea is 10,000 square miles large', neither by 'North Sea', nor by ' 10,000 ', does one refer to a condition or process in his inner 
life, but one states something entirely objective; entirely independent of such things as our Vorstellungen. If, say, we were, on some other occasion, to want to draw the boundaries of the North Sea differently, or wanted to understand something else by ' 10,000 ', the same content would not thereby be false which formerly was correct, but rather, a true content would perhaps be replaced by a false one; by which the truth of that first one would be in no way abolished $(1884,34)$.

The main idea here is that the phenomenon of being true is in no sense psychological, and not amenable to psychological investigation. Two further ideas are worth noting. First, there is some room for free choice as to how one will represent things as being; but no corresponding room for choice as to how what was thus represented as something is. Where things were represented truly as such-and-such, things may be represented falsely in representing them as being something else. One thus changes how things were represented. One cannot change what there is to represent as one thing or another. Nothing one can do can change what would have been representing truly into what would not be. Changing how one represents Sid is not changing Sid. Such is objectivity. The core of this idea of it might be pushed in various directions. Some version of it, worth exploring, lies in young Wittgenstein's idea that tautologies and contradictions are not properly thoughts (truth-evaluable) at all.

A second idea is this. How one draws the boundaries of the North Sea is, to an extent at least, up for grabs. But for anyone to think about the North Sea boundaries must be drawn somehow. It must be determinate enough what it is, e.g., on whose being saline or cold the truth of some given representation is to depend. There must be how we think things to be in thinking the North Sea to be such-and-such; hence what it is we are thinking to be that such-and-such. One might thus think: whatever its boundaries may be, to think that the North Sea is saline one must have the (a) concept of the North Sea. We must grasp what it is that would count as saline if what we thus think is true.

This last idea is prima facie not implausible, even though developed one way it would lead straight to a vicious psychologism. Consider, though, Catriona, who, from a very isolated part of the 
mainland, has never heard spoken of such a thing as the "North Sea", though she makes an annual expedition to its shores, hoping to pass her summer (both days) by the sea (having no idea whatever of any bounds to this sea, or none more than that, most likely, it has some). Dipping her toe into the surf, she notes that the sea seems much colder than usual this year, and (observing the waves as she pulls her sou'wester closer around her) much rougher as well. Cat has no idea of drawing any bounds, especially any arbitrary ones, around any area of the earth's water-covered surface, or of calling the sea in which she dips her toe anything except, perhaps, "the sea". Nonetheless it is the North Sea into which she dips her toe. And it seems not unfair to report her as thinking that the North Sea was unusually cold and rough that summer (both days).

If that parcel of ideas with which we started is what points to what it would be to have a concept, then it seems that Cat can have no concept of the North Sea. Her mind is empty in re where boundaries should be drawn around that in which she dipped her toe; she is quite innocent of the idea that there is any such thing as "the North Sea". She (or her toe) is simply in it. So, it would seem, having the, or even a, concept of the North Sea is incidental at best to having thoughts about it. In light of all this, the idea that having concepts has any significant, let alone central, role to play in either a psychology, or a philosophy of mind, whatever exactly having a concept is going to be, appears threatened. Or rather, perhaps, the right role for it is not yet in sight.

2. Whole Thoughts First: There is a certain class of mental phenomena, which consist in standing in some determinate way, or other towards some way there is for things to be. One may take this to be a way things are, or resent it's so being, or lament it's not. Or one may break into cold sweats at night when beset by the thought that it is a way things may become. And so on. Such is a wide, though not exhaustive, area of the mental. It may feel to one, lying too long in the sun, as though a swarm of ants is crawling across the back of his bare thigh. Such falls in the class. Or he may simply feel a swarm of ants so crawling. Such does not. Anyway, the class is wide enough to be important. 
In my Unshadowed Thought I discussed a few of the objects of members of this class, and standing towards them in at least some of the ways which fall within it. Part of the idea was that it is an occasion-sensitive matter how the (grammatical) objects of members of this class are to be counted. At that time, though, I still read Frege as a target. In the interim I got to know him better. Reading came to replace hearsay at various crucial points. I now see Frege as font of just those ideas, which generate contextualism in this domain; crucially of the right non-psychologistic conception of having concepts. His two most crucial ideas for this purpose are: first, the idea of putting whole thoughts first, and second, the idea of the essential publicity of thought.

First the idea whole thoughts first. One early expression of this idea is in a letter to Anton Marty in 1882. Here the central point is put thus:

I do not believe that concept formation can precede judgement, because this presupposes an independent existence of concepts, whereas I think a concept arises through the decomposition of a judgeable content $(1882,118)$.

"Judgeable content" is Frege's early term for 'that by which truth can come into question at all'. It fits a particular conception of this, which Frege would come to reject, thus replacing "judgeable content" with "Gedanke" for the core idea rightly conceived. Frege often speaks of concepts as not capable of having an "independent existence". Sometimes he seems to associate this idea with their unsaturation, or need of completion: there must be objects, which fall under them, or not. Sometimes, though, the point is more that one can identify a concept only by the role it would play in a thought. The idea goes through versions. The simplest will do here. To grasp what any given concept is one must grasp what it would be for it to be true of something (or, in a variant, for it to take on the value true for that thing as argument). "True" expresses precisely that notion which it is a thought's business to bring into question: being true, thus being true outright, is just what it is the business of a thought most fundamentally to be. 
Several ideas go with this conception of the relation of whole thoughts to concepts. First, there is a classical philosophical problem, which simply disappears on this way of looking at things (though, as we shall see, at a price). The presupposition of this problem is that it is possible to specify the elements in a thought while leaving over a residual question what it is that binds these elements into a thought (rather than, e.g., merely a list of elements), where this question would require some sort of substantive answer. But, if we begin with a whole thought and carve it up - break it up into parts - then, as with a goose, if it is only carving that we did, the result should just be the whole thought, carved up. The parts can do no other than, jointly, constitute the whole thought. What did not do this would not be a (mere) decomposition.

A good comparison here would be this. If the thing in question is whitewashing a casita in a Pueblo Blanco, the finished product is a whitewashed casita. If you have that product then you have a whitewashed front façade, a whitewashed rear façade, and, for any other part of the casita's exterior you care to mark off, that will be whitewashed too. (Bracket shutters, window frames, doorknobs, etc.) Mark off parts as you like. But if the casita is whitewashed, any such part will be white. To have a decomposition of the whitewashing would be to have some set of surfaces such that for them all to be whitewashed is for the whole casita to be.

Here we are thinking of a task, or its completion, as what is to be decomposed. Such is a good way to think of a thought. A whole thought has a mission: to be that by which truth can come into question at all. (See, e.g., 1918, 60.) To perform that mission is to make truth turn in some determinate way on how things are. It is, one might also say, to fix a determinate question of truth, something admitting of the answers, "True", or "False". Such a mission can be decomposed into sub-tasks. Each of these, would be making truth turn, partially, on such-and-such. For example, if the whole thought makes truth turn on whether Sid smokes, a sub-task might be making truth turn on how Sid is; another might be making truth turn on who smokes. The idea applies in this guise. You have a decomposition of the thought that Sid smokes only if those ways of making truth turn partially on 
such-and-such, all engaged in simultaneously, just would be making truth turn on whether Sid smokes. The parts of a decomposition would then be thought-elements as I will use that term here.

The core idea here could be put: a thought is not constructed out of some pre-existing stock of potential elements as a sentence is constructed by a syntax out of some pre-existing vocabulary. If not, then multiple decompositions of the same thought are in the cards. On which Frege tells us,

I do not think that for every judgeable content there is just one way in which it could be decomposed, or that one of the possible ways can always claim priority for serious purposes (Ibid).

The casita above illustrates perfectly the idea here. There are indefinitely many ways of dividing the outer surface of the casita into subsurfaces. Any way of doing this would be a way of decomposing the whitewashing, just so long as it leaves no part of surface out. Which leaves many ways this might be done. A whole thought has a certain generality about it. In brief, there is an indefinite range of possible circumstances for which the answer to its question of truth would be yes, and/or to which the answer would be no. Such generality can be thought of as the resultant of all the contributions to generality of its constituents (on a decomposition). For any given thought there are many ways for constituents, on some way of carving them out, to add up to the generality of the whole thought as their resultant. For the moment, such indicates the underlying idea well enough.

One more point. Suppose you set out to whitewash the casita, forgetting that it has one exterior sidewall. When you are finished, the front and back façades are whitewashed. But the casita as a whole is not. It is only partly whitewashed. No one can set out to construct a thought. There is no such thing as that. But it is worth stressing that nor can there be something which is a partial decomposition of a thought (except as marked out within some whole decomposition of a thought). Truth may turn on how things are, e.g., on whether Sid smokes. It can 
turn on who smokes in turning on whether Sid does. But it cannot turn on who smokes simpliciter. There is no such thing as a partial turning of truth on how things are, where there is such a thing as a partially whitewashed casita. Such is a version of Frege's context principle.

So far, the term "concept" lacks a role. At one time or another Frege suggests various things a concept might be. Best here to avoid getting bogged down in sorting through them. I think it will serve present purpose to think of a concept as follows. Where there is a way for a thing to be, there is, correspondingly, the concept of (a thing) being that way. Someone may be such as to smoke, so there is the concept of (a thing) being a smoker. Similarly for a way for a pair of things to be, or more generally for an n-tuple of things to be, for any $n$ including zero. On this conception, the concept of being such-and-such is intrinsically tied to the relevant way for a relevant n-tuple to be: being that. For an object to fall under a given concept is just for it to be that way which that concept is of an object's being.

Thought-elements as presently conceived are not concepts on any of the usual conceptions of one. A thought-element (on a decomposition) is in the same line of work as the whole thought it is part of: making truth turn on how things are. The element does part of this. Such is essential to the disappearance of the problem of the 'unity' of the thought. A concept is not in that business. On our present conception of one, it does not represent at all. It may relate to Sid in this way: he may "fall under", or "satisfy" it: he may be that way for a thing to be which it is a concept of. If you like, you may then say that the concept is true of him. But it does not represent Sid as anything. It does not do anything it could not do but for Sid. The concept of being a smoker fixes a condition Sid may, or may not, meet - as a thought does in representing things as some way there is for them to be. If Sid falls under the concept smoker, such is simply the way things are, whether so represented or not. Such is reflected in the fact that whereas a decomposition of a thought provides a list of tasks such that performing each of these in performing all the others just is doing what the thought does, moving from it to those objects and concepts (ways for things to be) on which it makes truth turn yields only a list. 
One might see concepts as aloof from the objects to which they may (or may not) relate. Such aloofness is essential to that particular generality which they contribute to a thought. In general (not always) concepts are liable to be satisfied by other than what does, or by nothing, or by just one thing, without thereby ceasing to be perfectly respectable concepts. Thought-elements, where they occur, are not thus object-independent.

One more notion still remains to be introduced. It is that of (someone) having a concept. Such, one would think, is a form of knowledge, or understanding. To have the concept of being a smoker is to grasp what it would be for someone to be, or fail to be, that; that is, to be equipped (and prepared) to recognise what would, what would not, count as a case of someone being that. It is thus, one would suppose, to have a certain capacity, one to navigate the relation between the concept (or its relevant way for a thing (or n-tuple) to be) and those conditions of the things there are which are their being such as to fall under the concept, or not to.

Understanding having a concept on some such lines, it may seem at first sight that we have made little progress with Catriona. For she conspicuously lacks the capacity that would make for her having the concept being the North Sea. But we do now have the idea that a thought is something decomposable in many different ways. Decompose the thought that the North Sea is cold into an element, which binds it in the singular way to a certain object, namely the North Sea, and Catriona's lack of a concept of the North Sea may seem to put thinking that thought out of her reach. Who knows, though, in what other ways that thought may be decomposable? On some other decomposition, perhaps, no such obstacle appears to her thinking it: there is no mention of the North Sea. Perhaps, if given concepts are needed to think a thought, then which these are is relative to a decomposition, where (trivially) thinking it on some decomposition will do for thinking it. Perhaps this is the way to think of things. But it is no help yet. We must see in what ways the same thought may be decomposable. And this we will not see without a proper understanding of the notion same thought. This, I will suggest next, requires understanding the essential publicity of thought. 
3. Publicity: The idea that having thoughts requires having concepts, misunderstood, can lead us straight back into a fruitless psychologism, or, in other words, into the scientism of our times. But the idea itself need not do this. Frege's idea of the essential publicity of thought is a good prophylactic against this. Here are two expressions of it:

By thoughts I understand, not the subjective goings-on in thinking, but its objective content, which is capable of being the common property of many (1892: 32fn).

One can understand by the existence of a thought that the thought can be grasped as the same by different thinkers (1919: 146).

Vorstellungen in Frege's sense are what are essentially attached to some given bearer: the life of a Vorstellung is exhausted in its life as an object of consciousness of such-and-such thinker. Two thinkers cannot share a Vorstellung. Its life is over when it ceases to belong to so-andso's consciousness. A Vorstellung cannot be an object of judgement (of thinking something so) in this sense: no thought can make truth turn (ineliminably) on how such-and-such Vorstellungen are - on whether they are thus, or rather so. There is no such thing as that for truth to turn on. Thoughts, then, are always about what does not belong essentially to any given thinker's consciousness. Nor, then, do they themselves so belong. Thus thoughts are intrinsically shareable.

To say, then, that Cat takes Sid for a Sassenach is to say her to have a feature liable to be in common to her and an indefinitely extendible range of other thinkers. (Sid may go down in history, inaccurately, as one of the last great Saxons, as the Scots understood that epithet.) One need not be her to think what she does in thinking Sid to be a Sassenach. What feature must one share? One way to answer this question would be to identify all the thinkers who would count as thinking this thing of Sid. Just as one might investigate all the ways there are for the contents of a glass to count as beer - what variations are permissible - so, in the same spirit, one might investigate what variations are permissible within the range of those who would count as thinking Sid a Sassenach. 
The idea here generalises to a general plan for ascribing belief, or judgement. If such is our project, we might begin with a list of ways for things to be. These may be of interest for any of various reasons. We are sure these are ways things are; we are interested in knowing who else is so enlightened. Or the opposite: we are interested in who is so benighted. Or, again, we do not know whether things are these ways. Someone else's taking them to be (depending, of course, on how this is) might give us good reason to think so. Mutatis mutandis for thinking not. If Obama says the US bugged the EU, well, he ought to know. We thus identify a range of possible objects of belief. We identify these as it is open to us to do so. We may then encounter a multitude of reasons for counting others as believing these or not.

Often those reasons, which would sway us, have to do with bearing. Take Cat, for example. Suppose the thing to be believed or not is that the North Sea was unusually cold this summer. Cat is rather authoritative on that issue. Her memories of tingling toes as sensation slowly came back in them are fresh and salient. Her thinking what she does of what is, as it happens, in fact the North Sea gives us most excellent reasons for thinking the same of it. And that gives us excellent reason for counting her as thinking that the North Sea was unusually cold this summer. Such explains the initial example's working as it did.

The idea so far might be put thus: whether Cat believes suchand-such may depend in some way or other on what is 'in her head'; but what is in her head does not identify what there is for her to believe or not. There is a route from what there is to be believed or not to what, in particular, Cat does. But there is no route from what is in her head - from her way of thinking of the world - to what it is that she believes. The goings-on within her head under-determine what there is to be believed: they, on their own, do not fix how the ways there are for things to be may be identified. Bracket Cat and find something there is to be believed or not. Now unbracket her. The reasons there may be for counting her as a believer or disbeliever are, as one might put it, legion. Which ones tell depends in general on non-psychological considerations. Whether her thinking as she does bears in a given way on what one is to think, or on whether she is benighted or enlightened - a 
question on what bears on what - is, if not exactly a logical question, at least a question of what reason dictates as to the thing to think.

Misreading the idea that thinking thoughts requires having concepts might send us off searching in a quite different direction. If to think that the North Sea is cold one needs to 'have a concept' of the North Sea, then, lured in this direction we would hope, by closer examination of Cat, to find, or fail to find, in her head that particular mental construction which merits the title 'having the concept North $S e a^{\prime}$. If we find it, then perhaps she thinks the North Sea was cold this summer. If we fail to find it, then she cannot think this. Such is a picture of the way for belief to be in the head. But, the suggestion now is, it is a bad picture. Frege's idea of publicity forces on us another. Whether Cat's standing as she does towards things is her thinking the North Sea cold is liable to depend on considerations entirely extraneous to her subjective goings on - e.g., on what expertise as to the North Sea's status might require.

Other things matter besides bearing. 'Sassenach' is pejorative. It is no longer so that thinking someone a Sassenach is just, or even, thinking him Saxon. If Al were to say, 'Cat thinks Sid is a Sassenach', with whom would responsibility for the pejorative lie, Al or Cat? Must Cat be seeing Sid pejoratively for the attribution to be true? Well, there are various ranges of thinkers to whom one may be assimilating Cat in so describing her. There are those who would merely classify Sid as with south-of-the-border origins. There are those who would do so disparagingly. (And significant sub-ranges of each sort.) There are, correspondingly, various understandings of thinking Sid a Sassenach, and occasions for each. The answer to our question then depends (as, on reflection it does depend) on in what way $A l^{\prime}$ 's words are to be understood. Here is another way in which how Cat must be to be as said to be in words such as $\mathrm{Al}^{\prime}$ 's depends on considerations quite different from ones of what is in her head.

The picture publicity thus mandates can be seen as an adaptation of Frege's idea of putting whole thoughts first. Just as concepts cannot have an independent existence, but arise only through the decomposition of a whole thought, so, on our new picture, particular holdings of a 
belief cannot have an independent existence but arise only through the decomposition of a thinker's whole way of standing, his whole posture, towards the world. It is his whole posture which makes him count, or fail to count, as thinking some thing there would be to think anyway, with or without any attitude on his part towards its being so; in general, with or without his thinking at all. Correspondingly, particular things to be believed arise through the service to be performed in a given situation by distinguishing one thing to be believed from another; the point there is in ascribing a given belief, so that one rather than others. Just as a whole thought is decomposable in many different ways, so that what is an element of it on some of these ways may well fail to be on others, so a whole posture towards the world - taking things to be as a given thinker does at a time - can be decomposed in many different ways into thinking this, that and the other, where the particular things one thinks on one such decomposition will not be those one thinks on some other. Such gives content to the idea that beliefs are not in the head (or at least are underdetermined by what is there).

Suppose we allow ourselves to speak of 'the way Cat takes things to be'. Think of this, perhaps still more broadly, as her picture of the world - the way she sees it as treatable. Then, just as a thought may be decomposed into elements, so, too, this picture of the world may be decomposed into elements. Where our interest is in such stances as taking something to be so, these elements would be taking things to be such-and-such ways there are for things to be. In finding elements in the way Cat takes things to be we would be under an obligation to be sufficiently fair to her. This obligation, among others, may move us to the view that something can be an element in the decomposition of Cat's thought (into thoughts) only in the context of a wider plane for decompositions. Suppose Cat does not use 'Sassenach' as pejorative, but would use the term of Sid. In her case all she means by the term is, affectlessly, English. So she has been raised. Here again counting Cat as thinking Sid a Sassenach calls for understanding as to what so thinking would involve, and sometimes would be just wrong. The general point, though, is just that there are alternative ways of carving particular beliefs out of Cat's belief. How her belief is to be carved up on an occasion 
is fixed in one way by what we, the carvers would anyway count as different ways of describing belief.

One might see a reverse side to this coin. Suppose Cat does think that the North Sea is unusually cold this summer. By hypothesis she cannot recognise this as an expression of what she thinks. But she can express herself - plainly and clearly as a rule. And here, at least, it is in the ways she can express her thought that we find what qualifies her as thinking what she does about the North Sea. She might, e.g., say, 'How cold it is this summer!', referring by that 'it' to the sea in which she dunked her toes. What this suggests is: perhaps there must be other ways of expressing that thought which is the thought here that Cat thinks, and also the thought that we expressed above in 'The North Sea is unusually cold this summer'. On this way of thinking of Cat and her place in the universe of thinkers, there is one thought, expressible in the last-mentioned way and also in various ways Cat is prepared to express herself. Such is one way in which a thought would be multiply decomposable. But it is so only on a notion of same thought which permits such multiple expressions.

The notion same thought belongs intrinsically with a thought's publicity. It is we the ascribers, and not Cat the subject, who decide how thoughts are to be counted (on some occasion) in saying what it is that someone believes. When the same thought would be mentioned, or expressed, twice is not a psychological question. What sort of question, then, is it? What, if anything, about it might make same thought occasion-sensitive?

4. Counting Thoughts: Where do we find one thought expressed, or mentioned, twice? To answer this is to fix the notion same thought. Within a Fregean framework, this is the first point at which occasionsensitivity enters an account of thinking, or more exactly, that perviously mentioned class of stances, or postures, including thinking-so. It is not the only point. Nor am I suggesting that Frege himself would endorse the idea that the answer to the question is occasion-sensitive. But good enough reasons for saying so are found in what he does say. I will now sketch them briefly. 
First, for Frege the question how to count thoughts is intimately connected with issues of proof. Perhaps this stands out most clearly in his discussion of a sort of generalisation on the notion same thought, that of one thought being contained in another. For example, he suggests $(1914,230-231)$ that we can see that the thought that Cato is mortal is not contained in the thought that all men are. This shows in the fact that to infer that Cato is mortal from the premiss that all men are we need an intermediate premiss, namely (he suggests) that Cato is a man. If that Cato is mortal were contained in the thought that all men are - as it would be if 'Cato' were a (highly polysemous) name - then this should follow immediately from the supposition that all men are.

I called the notion of containment here a generalisation on that of same thought. I meant: for A and B to be the same thought can be seen as a special case of this, namely, one where A is contained in B and B in A. We can see this, I think, in his 1891 introduction of the idea that a concept can be conceived as a function from objects to truth-values (an extension of the means by which a function might be expressed). Here he tells us, e.g., that ' $\left(2^{2}=4\right)=(2>1)^{\prime}$ ' is the expression of a true thought, identity being a relation between objects, and both ' $\left(2^{2}=4\right)^{\prime}$ and ' $2>$ 1 ' denoting the same object, namely, The True. One can say this about denotation, he suggests, because saying it is compatible with the (obvious) fact that each of these expressions expresses a different thought. How do we know this? Frege makes a comparison with a more mundane, non-arithmetical, case. We can, he suggests, see 'The Morning Star has an orbital period smaller than the earth', and 'The Evening Star has an orbital period smaller than the earth' as expressing two different thoughts. Why say so? Well, he suggests, "One who did not know that The Morning Star is The Evening Star could hold the one true and the other false." (p. 14) For such a one, proof that The Evening Star has an orbital period smaller than the earth's would not come immediately from the Morning Star's having an orbital period smaller than the earth's, but would require an intermediate premiss. Where such was so, the first-mentioned would not be contained in the second, so that these must count as two different thoughts. 
In mathematics (e.g., in set theory) if one asked whether something followed immediately or only mediately from something else, the question might sometimes be as to whether it was derivable immediately within some particular system (formalisation); or if it is not yet such a question, then it would have to become so for it to have a definite answer. But if one thought that there were a good sense in which some mathematical propositions just do follow immediately from (or depend precisely on) such-and-such others, where others just do require longer paths of derivation, then the relevant sense of 'follow from' would involve one in the epistemology of mathematics - in something like the way in which one is immediately involved in epistemology if he asks whether the thought expressed thus: 'The Morning Star burns bright' follows immediately from the thought expressed thus: 'The Evening Star burns bright'. Here where we talk about following from, or being proved, what we have in mind is a notion of proof on which one can have, or be offered, or be provided proof. In the visible presence of that pig standing across my path I can sometimes have (or count as having) proof that there is a pig before me. Sometimes things cannot work that way: for one reason or another, in offering me the visual awareness it does, in fact awareness of a pig, sight cannot then thereby be furnishing me with proof that there is a pig before me.

Where I do thus have proof, that a pig is present is revealed to me by its palpable, visible presence. Where not, though the pig may still be ever so visibly before me, that sort of proof is not thereby on offer. Where the question is in this way epistemological, all of the vicissitudes, and all of the fluidity, of enjoying an epistemological status come on the scene. Briefly put, epistemology must work on terrain in which what is proof of what must be distinguished from questions of how things might conceivably be, or have been. And work within that sort of territory must, in the nature of the case, be occasion-sensitive work.

At midnight, over what they swear will be their last glass of the night, Pia asks Sid whether Venus is burning bright tonight. Sid, butter knife in hand, steps outside to see. At 12:02, staring at the clear sky above Marvão, he is confronted with Venus burning bright. He thus 
gains (we will suppose) immediate proof of the truth of a thought, of Venus, that it is burning bright - a thought which he inwardly expresses to himself, say, in those words just used. But does he also thus gain proof of the truth of that thought about whose truth Pia asked? Here is a way for things, just barely conceivably, to have been. At the time Pia asked her question Venus was, in fact, not burning bright. Some strange chemical reaction on that planet briefly blocked it from reflecting sunlight. Or it was eclipsed by a hitherto unknown astronomical phenomenon, on its one and only occurrence. No such thing did, or, perhaps, even could, have happened. Sid observed Venus on a perfectly ordinary night in its career, and thus did gain proof of the truth of the thought he expressed to himself silently. If the thought he thus expressed to himself just is the thought about whose truth Pia asked, then Sid also gained proof of the truth of that thought (since there is only one thought in question). So Pia, too, can gain proof of the truth of the thought she asked about when (old reliable) Sid tells her what he saw. But Pia could not have such proof if it might have been that at midnight there was a weird astronomical event of the genre just described. In which case the thought about whose truth she asked cannot be the same thought as the one for which Sid gained proof. For one might have proof of the one without (absent intermediate steps) proof of the other.

So, it seems, if every way we can (even barely) conceive of things having been is, straight out, a way things might have been, then no one ever has expressed, or ever could express, the same thought about Venus (or about anything) twice. Such would lose for us, as Frege puts it, an environment about which for us to make ourselves liable to risk of error in judging the things we do. Which, given the essential publicity of objects of judgement, would lose for us judgement überhaupt. On the other hand, it is hard to see how any conceivable eventuality could ever be ruled out absolutely as something the possibility of which (such as it is) might, in unusual enough circumstances, bear on such things as whether Sid offered Pia proof of that of which she asked. There is no invariably right answer to the question what would be proof for Pia then as to - what would make her a knower of - that of which she asked. 
The only alternative to that which preserves for us an environment of which we judge is an occasion-sensitively correct answer to such questions on particular occasions for ascribing to Pia a certain epistemic status as a knower (or not) of some given thing there is to know. This, in turn, entails that same thought is an occasion-sensitive notion.

Here, then, is one point of entry at which occasion-sensitivity becomes an obligatory part of any adequate philosophy of mind. But to cast this point in its proper light one further point is needed. It concerns one particular place, among others, at which there is room for there to be two thoughts rather than one. Suppose we ask how many thoughts there are, all of Sid, all of the same way for an object to be - say, of (someone/a thing) being a smoker. From what perspective is this question to be answered (assuming, for the moment, that it is a sensible question at all)?

One point to make here is that the answer to this question is not to be read off of the means involved in some particular expression of some such thought. By which I mean the following. Suppose Pia now expresses some thought, of Sid, that he smokes. She might do that in uttering any of a variety of different words. She might, e.g., say, 'That bemused looking guy sitting on the settee with a stuffed tomcat under his arm smokes'. One lesson we should all have learned by now is that such details of the manner of expression of a thought are more or less irrelevant (or anyway in no way directly relevant) to what identifies the thought expressed as the thought it is. To recapitulate in brief, expressing a thought (an act of creating representing) is an act of representing only insofar as it is recognisable as the representing it is (as to be understood as representing things as being as it does). The words we use to express a thought have this as their mission: to make such representing recognisable as what it is. The function of such words as 'The bemused looking guy...' in this mission is to make it recognisable who it is who is being said to smoke. They achieve this mission just in case there is something - presumably a guy - which is the thing of whom one would suppose the thing in question to be said. That different words might achieve the same end in different ways is compatible, so far as it goes, with there being precisely one thought, of Sid, that he smokes. 
The role of language, the idea is, is to serve in achieving recognition. David Kaplan, as I read him, exploits this point to defend Russell's view of the matter as against Frege's. Russell was always suspicious (to say the least), of the idea that there is such a thing as a thought-element whose work is to make the truth of that thought turn on how suchand-such object is. He was then doubly suspicious of the idea that two thoughts could differ precisely and only in containing two such different elements, while remaining about the same object. In a slogan, if there are such Sinne as just mentioned, the relation between them and objects thus picked out cannot be many one.

Russell's suspicion rests on the idea that such a thought-element would need to be descriptive, in a sense of 'descriptive' in which a description is, intrinsically, something which might have identified something other than what it does (or nothing rather than something, or vice-versa). Russell thus misses a possibility, which Frege underlines. There is nothing wrong with the idea of a concept of being (in Frege's terms) that very object such-and-such - e.g., that very man Cato. Such a concept would differ from, e.g., that of being a smoker in at least two respects. First, but for Cato there would be no such concept at all. (An exceptional case in re object-independence). Second, if there is such a concept then one and only one thing could ever satisfy it, namely, Cato. For, trivially, whatever satisfied it would be Cato. A thoughtelement, which put such a concept to work, would not be descriptive in the above sense. Such thought-elements once allowed for, there is then also room for the idea of many such for each object. Russell's suspicions were simply misplaced.

One may thus, agreeing with Kaplan, take the point that the mission of language is recognition, while still allowing, first, that Frege is right about thought-elements which make a thought singular (which bind it to a given object in the singular way), and second, that there may be different such ways of binding a thought to a given object. Whether there are is simply a matter of what distinctions are needed between one thought and another if our way of counting thoughts is to mesh as it must with the facts of what would (and what not) be proof of what. To see how this purpose would be served, we need to see from what 
perspective such verdicts might be delivered, or, again, in just what sorts of circumstances there would be such a purpose to be served. Here we return to Frege's insistence on the publicity of thoughts, that is, of the things there are to think. That point can now be generalised to cover both main forms of representing-as: representing in the form of a stance or posture, e.g., taking something to be so; and representing in the form of an act - expressing a thought, e.g., in taking something to be so. Pia performs the act she does, or holds the (whole) posture towards the world she does. There are then occasions for ascribing to her particular beliefs, such as some one to the effect that Sid smokes, and, similarly, the expression of particular thoughts - e.g., one or another to that effect. Such ascriptions begin with an independent fix in place already on what things there are to serve as the objects of belief, or of expression. They thus already presuppose some way of counting thoughts. Which is to say: how thoughts are to be counted is not something to be discovered in viewing the details of particular expressions of thought, or of engagement in it. It may belong, e.g., to the circumstances in which there is call for us (or someone) to say what it is that Pia said that in them there is call to make given distinctions between things which may require proof, according to what would be proof of them. There may be some specific need, e.g., to recognise the possibility of having proof of the truth of some thought to the effect that a certain person - in this case, Sid - is, while yet lacking proof of the truth of some other which also happens to be a singular one of that same object, Sid, to that same effect. On other occasions there may not be.

We now have a parallel for saying things to our prior point about thinking them. What Pia beliefs - which thoughts she holds true - is, the prior point was, underdetermined by what (else) is in her head. Let her be as she is at a time. Still, we have no answer to the question until it is first settled, independent of her, in what ways one might count as believing one thing rather than another - just what sorts of distinctions there are to be drawn here. Similarly, suppose that, on an occasion, Pia expresses a singular thought, and suppose further - with Frege - that this thought, so decomposed, contains an element - a Sinn in Frege's sense - which binds that thought to some individual - say, to 
Sid. Suppose further, with Frege, that, given the individual thus bound to, there may be room for this Sinn to be any of many things. Then fix all the factors in the occasion of Pia's speech act which might be relevant to identifying how her words were to be understood. These, by themselves, do not yet fix any one such Sinn to figure as an element in (what would then be) the thought she expressed; so nor (where this is a question) which thought she expressed. For such depends, again, on when anyway we would need to recognise two different such Sinne, two different things for all those facts to choose between. In the sense in which belief is not in the head, one might say, nor is assertion (purely) in the circumstances of its making.

Often there is no call to distinguish different thoughts, all of Sid, all to the effect that he smokes. It is enough to think of questions of truth as distinguished from one another in a way which leaves just one thought - the one of Sid - to the effect that he smokes. But that this is sometimes the right way to count thoughts does nothing to suggest that it always is; even less to suggest that there is anything which is, occasion-independently, the right way of counting thoughts. We can construct cases (we should not be overly impressed merely by this possibility) in which we can get someone's thinking, or talking, properly related to that of the rest of us only by recognising something for there to be proof of as to Sid's habits, proof of which would not be immediate proof of (what then must be) something else there is about these for one to have proof of. Sometimes this need remains with Sid, and the relevant habit (e.g., smoking) fixed. That there is sometimes such need should not suggest that there is a given stock of thoughts, which are, precisely, those there are to think in thinking of Sid that he smokes. The right conclusion is rather that counting thoughts correctly is an occasion-sensitive matter.

For the sea around Cat's toes to be frigid is one thing. For the North Sea to be frigid is quite another. Or so we should sometimes say, sometimes correctly. Depending on the distinctions, which need drawing on some occasion for speaking of such things, taking the North Sea to be frigid may or may not require some capacity, and proclivity, to mark off some aqueous part of the earth's surface as the North Sea. 
What Cat counts as believing on the one sort of occasion for saying of her what she thinks - how her whole stance towards things might then be decomposable - need not be what she counts as believing on another (though there is only one occasion of her standing on the beach). Different ways for a thought to bind itself to the North Sea are one point at which such occasion-sensitivity can enter, but not the only one. A philosophy of mind cannot remain coherent while blind to such phenomena.

5. Epilogue: In this essay, following Frege's method of separating the logical (questions of being true) from the psychological (questions of holding true) I have followed out one strand in the notion of a concept. Concepts (now a purely logical notion) are, by nature, true of things. There is obvious priority here to the notion of truth, hence to a thought, in Frege's sense: that by which truth can come into question at all. (What determines a specific question of truth.) On this line of thought, concepts are carved out of whole thoughts. Their life is their role in contributing to what each of a range of thoughts would do.

The main body of this essay followed out the psychological implications of that idea. What I mean by 'psychological' in this case is the question just when someone would count as holding some particular thought true (as taking such-and-such to be so). Here is an idea about this: for each thing there is for one to think, there is a battery of concepts such that 1) these are the ones out of which the thought is built, so that 2) to be capable of having the thought-for it to be something one could believe or disbelieve - one would have to 'have' (whatever having is) just those concepts. Such is a special case of a more general idea. The more general idea is that we can discover what someone believes by, metaphorically, 'looking in his head'. What we need to see is the details of his psychological organisation, as fixed, perhaps by what he would say, perhaps by serious psychological investigation. Frege has led us to dispose of both the special idea and its generalisation.

The key point in Frege is that the same thought may be decomposed in many ways. Immediately, then, the most one could say on the lines of the special idea is that to have an attitude with a given thought 
as its content one must 'have' some battery of concepts into which the thought could be decomposed on some decomposition of it.

However, following out the above line of thought, and looking a bit more closely at why we credit people with thinking things, we came to a second - and much deeper and pregnant-conclusion. This second conclusion is that there is not - and could not be - just one right way of counting thoughts. By 'counting' I mean: answering the question where there are two thoughts, where one. The reason is, again, that a way of counting thoughts has particular purposes to serve. But most broadly, that way must get things right as to the epistemic status of both thinkers and things they think. For Frege, the stress here was to get things right as to what would be a proof of what.

In any event, here is one way that what thoughts there are is an occasion-sensitive matter. This being so, we get our conclusion right away. If what Catriona believes is fixed by what is in her head, according to that general idea above, then there should be one thing, which is the thing it fixes. But there cannot be. What true answers there are to questions as to what she believes depends on the occasion for posing them.

I am afraid, though, that all of this leaves us short of what really interests Jocelyn Benoist the most about concepts. This is because I have said too little about what concepts are good for. But it has set us on the right track. What we need to ask at this point is to ask why we decompose thoughts at all, and then why in the particular ways we do. To find an element in a thought, whether a concept or something else, is to present that thought as falling under some given generality, as the thought that Sid bathes falls into the category thoughts about Sid. To locate a given concept in a thought is to identify a sense in which it is the same as a range of other thoughts. Of course, given that thoughts are multiply decomposable, for a thought to be a member of some such range is just for it to have a decomposition that places it there.

So if a concept can be carved out of one thought, it can be carved out of a range of them. It identifies something shared in common by all members of that range. (This is not to say that it is determined context-independently what belongs to this range - just which thoughts are decomposable in the required way). There is point in carving out a 
concept from a thought, as, in general, there is point in decomposing it into, inter alia, some given element, just where there is some issue which arises, or arises in the same way, for any thought in the range thus identified, or, perhaps better, where for a thought to belong to that range would be for this issue to arise (in that way). The most central point in decomposing a thought in a particular way, for example, is to exhibit its inferential, or truth-preserving, relations to other thoughts; most particularly, those cases where truth is preserved merely by virtue of being true being the phenomenon it is. For example, there is a range of thoughts - that Pia folds paper, that Sid folds paper, that Leo folds paper, and so on - which all have the feature that if they are true then so, ipso facto, is the thought that someone folds paper. What these thoughts have in common is, first, that they involve the concept folding paper, and then how they do.

Now, one important feature of thoughts is that, in general, they are world-involving. Frege was aware of this point, though not as attentive to it as he might have been. One way they are world-involving is: what thoughts there are is a world-involving matter. Had Frege not existed, there would have been no thoughts about him. Had evolution not resulted in marsupials, there would have been, not only no thoughts about kangaroos (since they are marsupials), but no such thought as the thought that oxen are marsupials - as it stands, a perfectly good thought except for being false. But, if a thought's job is to make truth turn in a determinate way on how things are, then thoughts are also (in general) world-dependent in that how a given thought makes truth turn on how things are is liable to depend on how things are (beneath the stars, as they once said, or 'in the red dust', as the Chinese put it).

The idea can be put this way. A thought is identified by its way of making truth turn on how things are. If it is a thought that such-andsuch, it is also a thought of (things being) some particular way for things to be $-e . g$., such that smokers are outdoors, like coureurs de bois, are (today) both outdoorsmen. It is intrinsic to the thought to make truth turn on whether things are that way. But it may belong to a way for things to be that what things need to be to be that is to be decided, in 
certain ways, by how things are - in the way that what you must do to have table manners like Sid's depends on what Sid's table manners are.

The leader in showing us why we must recognise this sort of world-dependence, and how it works, is Hilary Putnam. A case might work like this. Pia insists that Sid keep a distance of at least 20 meters. Very well. But what would it be for Sid to be 20 meters from her? Such depends on how distance may be determined, which, in turn, depends (inter alia on the geometry of space. The geometry of space is, anyway, one determinant of how it is possible for the truth of 'the distance between Sid and Pia is less than 20 meters'. And one thing we know: there is such a thing as two things being 20 meters apart. There are plenty of cases of two things so relating. If not, then in an afternoon we could produce some. Here is a simple example, borrowed (at some remove) from Hans Reichenbach. One way to settle whether Sid is 20 meters from Pia would be to take a folding rigid measuring rod, carry it over to Pia, set it on the floor, unfold it in Sid's direction until it touches him, and look at what it says. Such a procedure would not work if the length of rigid objects changed under spatial translation (change of location) - not by being acted on, but just by virtue of the structure of space. In that case, the sort of thing, which does count as two objects being 20 meters apart is, no longer even a coherent way for anything to count as anything. If there being such a thing as Sid and Peter being 20 meters apart, hence there being such a thought as the thought that they are that, is to be indifferent to such vicissitudes of the way things are - as we would typically suppose it is - then, like how you must behave at table to be behaving like Sid, how two objects must be to count as a case of being 20 meters apart must admit of depending on how things are.

I think we are now at least closer to what matters to Jocelyn most. The truth of the thought that Sid slurps soup is certainly a world-dependent matter. Or so at least we hope. If not, we have nothing at all to think about. The present point can be put as one about, as Americans put it, 'going meta': we now want, not merely to represent things (e.g., Sid) as being various ways, but, standing back from that, to discuss the most general apparatus, or structure, of representing-as. For that purpose, we want to make assertions such as: 'The way Sid now stands 
towards Pia is one thing which would count as one object being 20 meters from another'. Our topic is now not, or not just, Sid and Pia, but the phenomenon of representation itself. And the point is: the truth of such thoughts, too, is world-involving.

Now, where there is world-involvement there is, per se room for occasion-sensitivity. Are Sid and Pia an item? Well, it all depends on what you call being an item. (When, and why, are you asking that?) But the phenomenon of occasion-sensitivity seems to some to threaten the idea of objectivity, hence the very idea of truth itself. The idea would be this. A thought makes truth turn in some determinate way on how things are - or at least is meant to. The way things are then presents us with the result of things so turning. There is, on the one hand, what it is that is represented as something, and, on the other, what it is thus represented as; and those two things together - and alone - must decide truth or falsehood if truth is to be decided at all. Now the circumstances of asking whether something is some given way can appear in this picture as an impermissible third factor.

But the outline of an answer to that threat is already contained in the very idea of representing-as. What there is to represent as being something, and what there is to represent something as being, are two categorically distinct sorts of things. What appears on one side of the representing-as relation is not the sort of thing, which could ever appear on the other. Objectivity resides in the very idea that when we represent something as something, what we so represent - what must be, or not, as we represented it (if anything is) is something whose being as it is is totally distinct from, and independent of, both the way we represent it, and the fact of our so representing it. Occasion-sensitivity in representing, so far as it goes, leaves that idea untouched. As long as that idea is untouched, objectivity remains. Not just 'all that we can attain to or our frame requires', but objectivity pur sang, an sich - the real thing. If occasion-sensitivity spreads to the 'meta' - to questions as to where there are two thoughts, where one, or as to exactly how some given thought makes truth turn on how things are - we need only ask ourselves whether we can still make sense of the idea of representingas at all. Can we recognise (often enough) when what was represented 
as so is so? How do we tell this? By, e.g., unfolding a rigid measuring stick, or substituting for this whatever the world dictates should be substituted? Or by seeing how we feel about it, or how we are inclined to represent things? So long as we can thus make sense of the idea of representing-as, we need not worry that, in some other way, objectivity might turn out to be all a sham.

Charles Travis 30 March 2014

\section{References}

FREGE, G. Letter to Anton Marty, 29 August 1882. In: FREGE, G. Gottlob Freges Briefwechsel. Hamburg: Felix Meiner, 1980. p. 117-119.

FREGE, G. Die Grundlagen der Arithmetik. Breslau: Wilhelm Koebner, 1884. (Bilingual edition. Translation J. L. Austin. Oxford: Basil Blackwell, 1978).

FREGE, G. Logik in der Mathematik [1914]. In: FREGE, G. Nachgelassene Schriften. 2. ed. Hamburg: Felix Meiner, 1983. p. 219-270.

FREGE, G. Meine Grundlegenden Logischen Einsichten [1915]. In: FREGE, G. Nachgelassene Schriften. 2. ed. Hamburg: Felix Meiner, 1983. p. 271-272.

FREGE, G. Der Gedanke. Beiträge zur Piholophie de Deutschen Idealismus, v. 1, n. 2, 1918.

FREGE, G. Die Verneinung. Beiträge zu Philosophie des Deutschen Idealismus, v. 1, n. 3-4, 1919.

Received: 10/14/2016

Recebido: 14/10/2016

Approved: 08/15/2017

Aprovado: 15/08/2017 